\title{
Publication Patterns of U.S. Academic Librarians from 1993 to 1997
}

\section{Ann C. Weller, Julie M. Hurd, and Stephen E. Wiberley Jr.}

This study examined the contribution to the peer-reviewed literature of library and information science by practicing academic librarians in the United States. Data on authors were obtained from articles published from 1993 to 1997 in thirty-two journals. Of 3,624 peer-reviewed articles in these journals, 1,579 (43.6\%) were authored by at least one practicing academic librarian. These librarians represented 386 institutions of higher education. This study provides benchmark data for publication productivity of academic librarians and identifies a core list of peer-reviewed journals for them. Approximately six percent of these librarians wrote three or more articles in the five-year period. In nineteen journals one-third or more of the articles were authored by academic librarians. Libraries from Research I universities that were members of the Association for Research Libraries were the most productive. The contribution of practicing academic librarians to the literature of their field is significant.

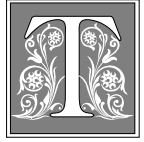

he literature on publication patterns in library and information science (LIS) usually focuses either faculty in LIS schools or practicing academic librarians. Both groups have made significant contributions to scholarship within their discipline. Both groups come from an environment that values research and publication, but each tends to bring a different perspective. Practitioners can make important contributions to the scholarly publications in a practice- based discipline. The degree to which practicing librarians contribute to the knowledge base of LIS is the focus of this investigation. To examine this question, the present study analyzed academic librarians' contributions to the peer-reviewed literature, documented their publication patterns, and compared these patterns with findings of earlier studies of publication patterns by academic librarians and LIS faculty.

Two recent studies have reviewed publication patterns of LIS faculty. Karen E.

Ann C. Weller is Associate Professor and Deputy Director, Library of the Health Sciences, in the University Library at the University of Illinois at Chicago; e-mail: acw@uic.edu. Julie M. Hurd is Associate Professor and Science Librarian in the University Library at the University of Illinois at Chicago; e-mail: jhurd@uic.edu. Stephen E. Wiberley Jr. is Professor and Bibliographer for the Social Sciences in the University Library at the University of Illinois at Chicago; e-mail: wiberley@uic.edu. The authors sincerely appreciate the advice of their colleagues who regularly attend the "research brown bag" in the university library and contributed to the discussions on the design and analysis of this study. They also thank Barbara J. Via for sharing the original list of journals she used in her study of editors. Her article listed only the names of the journals whose editors had responded to her survey. 
Pettigrew and Paul T. Nicholls studied LIS faculty in the United States during an eleven-year period (1982-1992). ${ }^{1}$ Their author-based study provided data on mean productivity per faculty member. They used the Directory of the Association for Library and Information Science Education, 1992-93 to obtain names of all fulltime faculty at the assistant, associate, and full professor levels. Each of the 607 names of faculty members was searched on five databases, retrieving a total of 7,937 publications. They found that faculty productivity appears to be influenced by the presence of doctoral programs, with publication output higher in schools with Ph.D. programs than in schools limited to master's programs. LIS faculty in Ph.D. institutions published a mean of 4.58 articles in refereed journals in the eleven-year period, whereas LIS faculty in institutions with master's degrees published a mean of 2.85 articles in refereed journals. The average number of published articles for this time period was 10.55 and 5.97, respectively, when nonrefereed as well as refereed articles were included. However, these differences became less pronounced when data from only Research I institutions were compared. Pettigrew and Nicholls found that LIS faculty from Research I institutions with Ph.D. programs published an average of 5.0 articles in refereed journals versus 4.6 articles in those Research I institutions with only master's programs.

Marcia J. Bates used a slightly different approach in a study of publications of LIS faculty. ${ }^{2}$ She compared publication patterns of senior LIS faculty from four LIS schools (Illinois, Indiana, Michigan, and UCLA) that "consistently rated high" in several measures of assessment. ${ }^{3}$ She found that senior LIS faculty in these four schools published a mean of between 6.3 and 8.0 journal articles, book chapters, and articles in conference proceedings from 1984 through 1991. These data did not separate peer-reviewed articles. Bates was hesitant to compare her data with other studies that grouped all publication types together, a practice she claimed "may obscure real differences between schools."
Several studies have investigated the authoring patterns of practicing academic librarians. Two similar studies published in 1985 examined the institutional affiliation of authors. Sylvia C. Krausse and Janice F. Sieburth conducted a study of LIS publication patterns based on articles in twelve LIS journals. ${ }^{5}$ Between 1973 and 1982, practicing academic librarians authored a steadily increasing percentage of published articles in the field, from 28.2 percent in 1973 to 42.3 percent in $1982 .{ }^{6}$ Krausse and Sieburth also found that the most prolific authors came from institutions with library holdings of more than one million volumes. ${ }^{7}$

The same year, Paula Watson published a study that compared authoring patterns of librarians in eleven major journals between 1979 and $1983 .{ }^{8}$ She found that 44.2 percent of authors came from academic libraries, and 20.9 percent came from LIS faculty and students. ${ }^{9}$ Watson did not differentiate data by year so it was not possible to determine whether the ratio of publications between LIS faculty and practicing academic librarians remained constant during the time period for the journals she studied. There was an overlap of eight journal titles in the Krausse and Sieburth, and Watson studies. Krausse and Sieburth's twelve titles came from LIS titles included in Social Science Index, whereas Watson selected LIS titles that were among the "best-known and most well-established journals in the field."10

In 1990, John M. Budd and Charles A. Seavey published the results of their study on the authorship patterns of academic librarians in thirty-six library science journals over a five-year period (1983-1987). ${ }^{11}$ Most individuals (90.7\%) authored only one contribution, as either a single author or a coauthor. The articles came from 384 institutions, just over onethird $(34.9 \%)$ of which were represented only once during the five year period. Budd and Seavey also found that of the twenty institutions whose librarians were the most productive, eighteen were current members of the Association of Research Libraries (ARL). They pointed out 
that the large libraries had "the benefit of numbers; their staff sizes are considerable. They also have broader and deeper resources-bigger collections ... [and] ... a research impetus on the campus." 12

As authors of nearly one-half of the articles published in journals studied, academic librarians make important contributions to the LIS literature. There have been no comparable recent studies. Several questions emerge: Do academic librarians continue to provide a significant proportion of articles in the peer-reviewed literature? What are productivity benchmarks for practicing academic librarians? What is the frequency of sole authorship and coauthorship for academic librarians? Do practicing academic librarians' who recently published come from institutions of higher education that have large collections, are Research I institutions, or are members of ARL?

\section{Methodology}

\section{Selection of Peer-Reviewed LIS Journals}

This study focused on the peer-reviewed LIS journal article. Generally, journals are the publication of choice for practicing academic librarians. Identifying an appropriate list of journals was the initial challenge. Budd and Seavey developed their own list of LIS journal titles to investigate. ${ }^{13}$ Mary T. Kim studied citation analysis using a core list of LIS titles. ${ }^{14}$ A study by Barbara Via provided another list of LIS titles. ${ }^{15}$ She surveyed editors of sixtyeight LIS journals to determine their editorial peer review process.

Budd and Seavey began their list with a combination of the twelve titles used by Krausse and Sieburth and the eleven titles identified by Watson. ${ }^{16-17}$ They then added other titles of "special interest" to produce a list of thirty-six LIS journal titles. ${ }^{18} \mathrm{Kim}$ expanded a list of thirty-one titles that David F. Kohl and Charles H. Davis developed in 1982. ${ }^{19-20}$ She added titles that were (1) listed as both citing and cited LIS source journals in the Journal Citation Report, (2) published by the ALA, or (3) referenced by journals in the original set of thirty-one titles. Her final list included fifty-two journal titles. Via built her list from the lists developed by Daniel O'Connor and Phyllis Van Orden and by Budd and Seavey. ${ }^{21-23} \mathrm{O}^{\prime}$ Connor and Van Orden's original list used thirty LIS titles that "accept contributions from members of the field and were indexed in Library Literature," and eliminated journals that solely published solicited articles. ${ }^{24}$

\section{Material published with symposia, conferences, and theme issues are chosen for a variety of reasons.}

The variety of ways that Budd and Seavey, Kim, and Via developed their lists indicates both the difficulty of identifying an appropriate list of journals and the somewhat subjective dimension of the process. Among these three lists were 103 different LIS titles. To compensate for a possible bias in any one list, this study used as a starting point those journals that appeared on at least two of these three lists. Forty-two titles met this criterion.

Because the investigators were interested in publication patterns of academic librarians in U.S. libraries, journals published outside North America were eliminated from consideration. Because this study was interested in the scholarly literature of the field, the investigators sought to identify the peer-reviewed journals from the remaining list of forty-two titles. The 'instructions to authors' sections of journals, which usually included information on the journal's review process, were examined for each title. If the instructions did not state explicitly that the journal's articles were peer-reviewed, the investigators contacted the editor to determine whether they were. The final list comprised thirty-two currently published, peer-reviewed LIS journal titles produced in the United States and Canada (see table 1).

\section{Identification of Peer-Reviewed Articles}

Not all the material published in a peerreviewed journal undergoes a formal review process. Typically, only articles are peer-reviewed. Journals contain a variety of other types of material. Thomas E. 
Nisonger found that over a twenty-year period, only 54.2 percent of the authored items in the journal Library Acquisitions: Practice and Theory were bona fide articles. ${ }^{25}$ In her study, Watson excluded "books, chapters in books, reports, and articles in more specialized journals." 26 Krausse and Sieburth excluded "book reviews, news reports, columns, editorials, etc." from their study. ${ }^{27}$ Budd and Seavey also excluded "editorials, book reviews, columns, and responses" to ensure that only full-length articles were included. ${ }^{28}$
Using criteria similar to those described above, the present study excluded all editorials, introductions, committee reports, letters to the editor, news items, columns or features, obituaries, and book reviews. Even with these exclusions, one cannot assume that the remaining articles in a journal are peer-reviewed. To ensure that only peer-reviewed articles were included in the data set, symposium and conference proceedings also were excluded. For that same reason, all "theme" issues that had a guest editor who invited contributions also were

TABLE 1

\section{Core List of Refereed Journals in Librarianship} (U.S. and Canadian Publications)

American Archivist*

Bulletin of the Medical Library Association*

Behavioral and Social Sciences Librarian*

College \& Research Libraries*

Canadian Journal of Information/Canadian Journal of Library and Information Science

Cataloging \& Classification Quarterly*

Collection Management*

Government Information Quarterly

Government Publication Review /Journal of Government Information*

Information Processing and Management

Information Technology \& Libraries*

Journal of Academic Librarianship*

Journal of Education for Librarianship

Journal of Information Science

Journal of the American Society for Information Science

Libraries \& Culture

Library Acquisitions: Practice and Theory*

Library and Information Science Research

Library Hi-Tech*

Library Quarterly

Library Resources \& Technical Services*

Notes: Music Library Association*

Online and CD-ROM Review

Public Libraries

Reference Services Review*

Research Strategies*

Resource Sharing and Information Networks

RQ/Reference \& User Services Quarterly*

School Library and Media Quarterly

Science \& Technology Libraries*

Serials Librarian*

Technical Services Quarterly*

*Journals with $33+$ percent U.S. academic librarian authors 
excluded. Material published with symposia, conferences, and theme issues are chosen for a variety of reasons. Authors are selected because of their subject matter expertise or because they participated in a presentation, symposium, forum, or conference. For whatever reason, these articles are published as part of a group of articles. The experiences of the investigators were that these types of articles often are not peer-reviewed. Excluding such articles may have eliminated some peer-reviewed contributions; however, these criteria provided one more level of assurance that only peer-reviewed publications were included in the present study.

\section{Data Collection}

To be certain that the data did not represent an anomaly in publication patterns that might be present within any given year, the study covered a five-year period (1993-1997). Budd and Seavey also examined data for a five-year period, ten years earlier than the present study, from 19831987. For each issue, the investigators recorded the date of publication, the number of peer-reviewed articles, the number of authors of these articles, the number of these articles authored by at least one academic librarian, and the number of authors of these articles who were academic librarians. From each peer-reviewed article that was authored by at least one academic librarian, the study noted the academic librarian author's name, his or her institutional affiliation, and the departmental and institutional affiliation of his or her collaborators. The investigators relied on the institutional affiliation information from each article to determine whether an author had an academic affiliation and to identify the institution. If the same author listed a different affiliation in separate articles, the names of each institution were recorded. The data set included only articles with authors from U.S. institutions.

The investigators entered all data into a spreadsheet program. Some authors were inconsistent, at times using their full first and middle names or other times using only either one or two initials. The investigators attempted to reconcile variant forms of author and institutional names; no attempt was made to reconcile name changes.

\section{Results}

The thirty-two journals published 703 issues during the time frame of this study. The investigators did not locate three issues $(0.4 \%)$ from two titles. Based on the percentage of articles authored by academic librarians in the other issues of these two titles, this study's data set probably lacks three to four articles (approximately $0.2 \%$ ) by academic librarian authors.

The thirty-two journals contained 3,624 peer-reviewed articles published between 1993 and 1997. Of these articles 1,579 $(43.6 \%)$ were authored by at least one academic librarian. In total numbers, there were 5,477 instances of authorship and 2,032 of these were academic librarians. Of these 2,032 names, 1,515 were unique academic librarian names (see figure 1).

Articles authored by academic librarians were not distributed equally among all the titles. Among the thirty-two LIS titles, the percentage of articles authored by at least one academic librarian from a U.S. institution ranged from 0.0 percent (Canadian Journal of Library and Information Science) through 100.0 percent (Technical Services Quarterly). The nineteen asterisked journals in table 1 are those in which a minimum of one-third of the articles were authored by at least one U.S. academic librarian.

In the data set, the highest number of peer-reviewed articles for one author was ten (see table 2). Academic librarians who published three or more articles during this time period comprised 6.07 percent of all those who published. Almost 80 percent of the academic librarians who published in these thirty-two journals were either a single author or a coauthor on only one publication during the fiveyear time period studied.

On average, there were 1.46 authors per article. For individual journal titles, the mean authors per article ranged from 1.02 (Libraries and Culture) to 2.07 (Online and CD-ROM Review). Of articles by academic 


\section{FIGURE 1 \\ Basis of Data Analysis for Publication Patterns of U.S. Academic Librarians}

- 32 refereed journals published in U.S. or Canada, 1993-1997

- 703 journal issues

- 3624 articles

- 1579 articles with at least one U.S. academic librarian author

- 1515 U.S. academic librarian authors from 386 institutions same campus or across institutional boundaries. Fiftyfour $(20.8 \%)$ of the collaborations were "intra-institutional," with scholars outside the library and from the same campus, compared to 206 collaborations $(79.2 \%)$ that were librarians, 869 (55\%) were single-authored works (see table 3). The remaining 710 articles $(45 \%)$ had two or more authors. Papers with three or more authors comprise less than ten percent of the total.

The data set was sorted by authors' institutional affiliation to produce a ranked list of the total author count per institution (see table 4). Most of the institutions in table 4 are large research universities where scholarly research and publication are important elements of the institutional culture. In fact, of the top twenty institutions, all but one with the most number of articles published by librarians was a Research I institution or held ARL membership. Ninety-five percent are ARL libraries, and 80 percent are Research I institutions.

The 710multiple-authored articlesincluded $260(36.6 \%)$ that demonstrated an "extramural" collaboration, whether across units on the "interinstitutional," with scholars, whether academic librarians or not, from other institutions. Of those intra-institutional collaborations, forty-two were with faculty from other units. Outside collaboration involved other academic librarians for eighty-one articles. Another fifty-three articles included collaboration with nonlibrarian scholars from other schools; thirty-two of these were LIS faculty. Twenty-three articles were coauthored withlibrarians from other types of libraries, and four were collaborations with students. Forty-five others included co-authors from a variety of institutions, including library vendors, government agencies, library associations, and consultants. Because the collaborations sometimes involved individuals from more than one extramural site, the number totals more than 260 .

\section{Discussion}

The discussion covers the productivity of academic librarians compared to the pro-

\begin{tabular}{|c|c|c|c|}
\hline \multicolumn{4}{|c|}{$\begin{array}{c}\text { TABLE } 2 \\
\text { Productivity of U.S. Academic Librarians from } 1993 \text { to } 1997 \\
(\mathrm{~N}=1,515 \text { authors })\end{array}$} \\
\hline Total \# of Articles & \# of Authors & Percentage & Cumulative \% \\
\hline 10 & 1 & $0.07 \%$ & $0.07 \%$ \\
\hline 8 & 2 & $0.13 \%$ & $0.20 \%$ \\
\hline 7 & 5 & $0.33 \%$ & $0.53 \%$ \\
\hline 6 & 2 & $0.13 \%$ & $0.66 \%$ \\
\hline 5 & 6 & $0.40 \%$ & $1.06 \%$ \\
\hline 4 & 26 & $1.72 \%$ & $2.77 \%$ \\
\hline 3 & 50 & $3.30 \%$ & $6.07 \%$ \\
\hline 2 & 236 & $15.58 \%$ & $21.65 \%$ \\
\hline \multirow[t]{2}{*}{1} & 1,187 & $78.35 \%$ & $100.00 \%$ \\
\hline & 1,515 & $100.01 \%$ & \\
\hline
\end{tabular}


TABLE 3

Coauthorship Patterns of U.S. Academic Librarians

(1,579 Articles Published 1993-1997)

\begin{tabular}{cccc}
\hline \hline Authors & Articles & Percentage & Cumulative \% \\
\hline 1 & 869 & $55.03 \%$ & $55.03 \%$ \\
2 & 574 & $36.35 \%$ & $91.39 \%$ \\
3 & 94 & $5.95 \%$ & $97.34 \%$ \\
4 & 21 & $1.33 \%$ & $98.67 \%$ \\
5 & 15 & $0.95 \%$ & $99.62 \%$ \\
6 & 5 & $0.32 \%$ & $99.94 \%$ \\
& 7 & $0.06 \%$ & $100.00 \%$ \\
\hline Totals & 1 & $99.99 \%$ & \\
\hline
\end{tabular}

ductivity of LIS faculty, the degree of collaboration within and among disciplines and institutions, and the productivity of librarians vis-à-vis their institutional affiliation.

\section{Productivity of Academic Librarians and LIS Faculty}

Each study that has examined the publication patterns of either practicing academic librarians or LIS faculty has used a different journal set, a distinct methodology, and a different time period. Therefore, any comparisons can only look for trends or general patterns and cannot be absolute.

The present study identified 1,515 academic librarians who produced 1,579 articles in thirty-two LIS journals over a fiveyear period, 1993-1997. Fifty-five percent of these articles were single-authored and,

\begin{tabular}{|lcc|}
\hline \multicolumn{1}{c|}{$\begin{array}{c}\text { TABLE 4 } \\
\text { Most Productive Libraries, 1993-1997 } \\
\text { (386 Libraries, Ranked by \# Authors) }\end{array}$} \\
\hline \hline & Authors & Articles \\
Institution & 35 & 46 \\
Pennsylvania State University & 32 & 32 \\
Cornell University & 31 & 40 \\
University of Illinois at Urbana-Champaign & 31 & 28 \\
University of Minnesota & 30 & 38 \\
University of Illinois at Chicago & 29 & 35 \\
Iowa State University & 27 & 41 \\
Ohio State University & 27 & 27 \\
Rutgers University & 26 & 25 \\
Texas A\&M University & 22 & 19 \\
University of Florida-Gainesville & 18 & 24 \\
University of Michigan & 18 & 12 \\
University of Nebraska & 17 & 26 \\
Northern Illinois University & 17 & 21 \\
University of New Mexico & 17 & 19 \\
Auburn University & 17 & 19 \\
State University of New York-Albany & 17 & 15 \\
University of Arizona & 16 & 14 \\
University of Colorado-Boulder & 16 & 14 \\
Kent State University & 16 & 14 \\
Harvard University & & \\
\hline
\end{tabular}


on average, any one academic librarian author published 0.96 peer-reviewed articles in the five-year period. Therefore, academic librarians who published produced 0.19 peer-reviewed articles per year in the thirty-two studied journals.

All the overlapping institutions and all but one of the top twenty institutions from the present study are either ARL libraries or Research I institutions.

The present study found that 43.6 percent of all published peer-reviewed articles were written by at least one academic librarian, compared to 34.4 percent in the Krausse and Sieburth study and 44.2 percent in the Watson study. ${ }^{29-30}$ As pointed out earlier, different lists of LIS titles were used in each study; however, seven titles overlap between the Krausse and Sieburth study and the present study. One finds that 46.5 percent of the articles in Krausse and Sieburth's seven overlapping titles were authored by academic librarians, whereas 62.8 percent from the present study were. Eight titles overlap between the Watson study and the present study. However, Watson assigned fractional credit to authors and institutions for multi-authored papers, so a similar comparison was not possible. As was noted earlier, the Watson and the Krausse and Sieburth studies included material that might not have been peer-reviewed.Assuming that the proportion of academic librarians writing refereed articles is the same as that of academic librarians writing nonrefereed articles, the comparison of data from the present study with data from the Krausse and Sieburth study suggests an increase in the percentage of material published by academic librarians.

Pettigrew and Nicholls found that all LIS faculty from Ph.D.-producing library schools published 4.58 articles in peerreviewed journals over an eleven-year period, or 0.42 articles per year for these LIS faculty. ${ }^{31}$ Faculty from library schools with master's degrees produced an average of 2.85 articles in eleven years, or .26 articles per year. A study by Pamela S.
Bradigan and Carol A. Mularski of a random sample of health sciences academic librarians found that this group of librarians published in numbers similar to LIS faculty. ${ }^{32}$ The survey had a 71.7 percent response rate and just over 50 percent of the respondents had published in a tenyear period. The respondents averaged .27 articles per year. Pettigrew and Nicholls located articles through database searching and searches on the names of the whole population of LIS faculty, whereas the present study obtained data from thirty-two journals and did not attempt to determine the percentage of academic librarians who publish.

In 1983, John Centra reported that two samples of 2,973 and 1,623 faculty averaged 1.7 and 2.5 publications, respectively, over a five-year period. ${ }^{33}$ Publications were not limited to journal articles. The second group included authors from institutions that placed more emphasis on research than the former group did. The number of publications averaged .34 and .50 publications per year, respectively. A multidisciplinary national survey of faculty in 1989 reported by Ernest L. Boyer found that, overall, 59 percent of faculty published five or fewer journal articles over the course of their careers. ${ }^{34}$

Even though these sets of data on the average number of publications per year are not directly comparable, what is clear is that the number of articles published per year by both academic librarians who publish and LIS faculty is less than one article per year. This output appears to be comparable to that of faculty in disciplines outside LIS.

\section{Interdisciplinary and Collaborative Publication Patterns}

More than one-third (36.5\%) of the coauthored and multiple-authored articles show collaboration, either within or between institutions. As librarians become more involved with teaching information access on their campuses and working with faculty in other fields who are using information technology in their teaching and research, collaborative publica- 
tion seems likely to increase. Several earlier studies examined collaborative relationship among LIS authors.

In 1988, Peter Hernon and Candy Schwartz, editors of Library \& Information Science Research, reviewed the contents of its first twenty volumes. ${ }^{35}$ Approximately one-third of the articles were coauthored, and 15.6 percent of all authors came from departments outside the library and schools of LIS, including management, business, communications, psychology, and education as well as students, consultants, and others from the private sector. However, Hernon and Schwartz did not provide data on how many of the $15.6 \%$ were collaborative projects with LIS faculty or academic librarians. A similar study by James L. Terry revealed that between 1989 and 1994, only 9.1 percent of all authors in College $\mathcal{E}$ Research Libraries came from nonlibrary institutions or organizations. ${ }^{36}$ Terry compared his study with Paul Metz's earlier study of authorship patterns in College $\mathcal{E}$ Research Libraries which found a larger percentage of articles originating from nonlibrary sources-12.68 percent between 1939 and 1979 , and 18.62 percent between 1980 and $1988 .{ }^{37}$ Terry and Metz only tabulated institutional affiliation for the first author. Data from the present study show that 72.96 percent of all the authors in College $\mathcal{E}$ Research Libraries come from academic libraries. The Terry and Metz data present gross numbers of institutional affiliations of individuals publishing in library science titles, but neither of these studies looked for collaboration within articles.

The present study presents benchmark data on the degree of both interinstitutional and intra-institutional collaboration of academic librarians. These data show that those outside the field of librarianship publish in the LIS literature and do collaborate with academic librarians.

\section{Institutional Affiliation and Librarian Productivity}

Table 4 lists those most-productive libraries with the highest number of published articles. Both the Budd and Seavey and the Watson studies identified a similar list of most-productive libraries..$^{38-39}$ Eleven of the top twenty (55\%) institutions on the Budd and Seavey list and nine of the top twenty $(45 \%)$ institutions on the Watson list are also in the top twenty institutions of the present study. All the overlapping institutions and all but one of the top twenty institutions from the present study are either ARL libraries or Research I institutions. Similarly, a study of authorship patterns from twenty years of the journal Library Acquisitions: Practice and Theory found that 56.5 percent of the authors were affiliated with ARL institutions. ${ }^{40}$ Mickey Zemon and Alice Harrison Bahr confirmed the smaller proportion of contributions to the literature by librarians from college libraries. ${ }^{41}$ They pointed out that academic authors from colleges were most likely to come from prestigious undergraduate institutions with a selective admissions policy.

The relationship between the characteristics of an institution and the publishing productivity of its librarians deserves further investigation. This study has shown that the size of the library and the prestige of the parent institution appear to be important factors. An overall institutional climate that supports research probably fosters it among librarians as well. Other variables also may be present because some large research libraries published less than smaller libraries. One could speculate that faculty status for librarians might have an impact on publication. Faculty status has many variations, with some institutions requiring substantial, peer-reviewed publications for tenure and others requiring different types of publication or professional involvement. Library size, institutional climate, and faculty status are all very complex factors. It was beyond the scope of the present study to explore the relationships of these influences to publication productivity.

\section{Conclusion}

Several trends have been noted. Academic librarians are contributing a very signifi- 
cant proportion of the LIS literature. The proportion of contributions by academic librarians to the scholarly literature may be increasing. Although the data are limited, it appears that academic librarians who publish do so as frequently as LIS faculty in general. Academic librarians at large research institutions with ARL and Research I standing publish more than librarians at smaller institutions. Single authorship is the norm, although coauthorship is very important. Collaborative endeavors between librarians and nonlibrarians occur within and across institutions. In all, literature in LIS has many types of authors.

Benchmark data on authorship and institutional productivity could be particularly useful for those institutions that either have promotion and tenure reviews for librarians or some similar evaluation that assesses scholarship. The data could provide a context for evaluating the records of individuals under review. In addition, academic librarians who aspire to build a research and publication record could use the present results to set productivity goals. These findings also could help professional library associations develop credentialing standards, similar to those used by the Medical Library Association's Academy of Health Information Professionals.

The nineteen journals that contained at least one-third of the articles authored by academic librarians could be considered a core list of peer-reviewed journals for academic librarianship. The list includes general titles such as College $\mathcal{E}$ Research Libraries as well as more specialized publications such as American Archivist. It illustrates the range of venues in which academic librarians publish reports of their scholarship and research. One would expect that academic librarians also would turn to these titles to provide evidence for decision making when seeking answers to theoretical or practical questions about librarianship.

Questions not addressed in this study suggest directions for future research. The present study does not investigate librarians' contributions to the non-peer-reviewed literature or the nonserial literature, as either monographs or book chapters, nor does it assess their publication of directories and annotated bibliographies, standard genres of the LIS field. The present study's examination of the peer-reviewed LIS journal literature is not a content analysis of this literature, nor does it address the motivation for those academic librarians to engage in research and publication. Additional work in any of these areas would provide a fuller understanding of the publication patterns of academic librarians and complement the findings presented here.

In ending this article, it is worthwhile to place publication by academic librarians within the contexts of the needs of the profession and the place of LIS in the academy. The rate of change of information technology is so rapid that there is a great need for scholarship that helps librarians understand what they must do to best serve their users. At the same time, to remain a learned profession, LIS must retain its place in the universities. As Alvin B. Kernan has argued in Death of Literature, no field of knowledge can continue to exist without such standing. ${ }^{42}$

The core group of scholars in LIS is the full-time faculty of LIS schools. These faculty number 600 , far fewer than faculty in disciplines such as chemistry and philosophy and professional areas such as law and medicine. Given the relatively small number of its core group of scholars, LIS needs the contributions of practitioners to meet the challenges of the information age and to bolster the standing of the discipline in the academy. This article has documented substantial publishing by academic librarians, particularly those from a number of ARL and Research I universities. It is important that they sustain their productivity and that others join them.

\section{Notes}

1. Karen E. Pettigrew and Paul T. Nicholls, "Publication Patterns of LIS Faculty from 1982-92: 
Effects of Doctoral Programs," Library and Information Science Research 16(1994):139-56.

2. Marcia J. Bates, "The Role of Publication Type in the Evaluation of LIS Programs," Library Information Science Research 20(1998): 187-98.

3. Ibid., 188.

4. Ibid., 193.

5. Sylvia C. Krausse and Janice F. Sieburth, "Patterns of Authorship in Library Journals by Academic Librarians," Serials Librarian 9 (spring 1985):127-38.

6. Ibid., 130.

7. Ibid., 132.

8. Paula Watson, "Production of Scholarly Articles by Academic Librarians and Library School

Faculty," College \& Research Libraries 46 (July 1985): 334-42.

9. Ibid., 336.

10. Ibid., 335 .

11. John M. Budd and Charles A. Seavey, "Characteristics of Journal Authorship by Academic Librarians," College \& Research Libraries 51 (Sept. 1990): 463-70.

12. Ibid., 466.

13. Ibid.

14. Mary T. Kim, "Ranking of Journals in Library and Information Science: A Comparison of Perceptual and Citation-based Measures," College \& Research Libraries 52 (Jan. 1991): 24-37.

15. Barbara J. Via, "Publishing in the Journal Literature of Library and Information Science: A Survey of Manuscript Review Processes and Acceptance," College \& Research Libraries 57 (July 1996): 365-76.

16. Krausse and Sieburth, "Patterns of Authorship in Library Journals by Academic Librarians."

17. Watson, "Production of Scholarly Articles by Academic Librarians and Library School Faculty."

18. Budd and Seavey, "Characteristics of Journal Authorship by Academic Librarians," 464.

19. Kim, "Ranking of Journals in Library and Information Science."

20. David F. Kohl and Charles H. Davis, "Rating of Journals by ARL Directors and Deans of Library and Information Science Schools," College E Research Libraries 46 (Jan.1985): 40-47.

21. Via, "Publishing in the Journal Literature of Library and Information Science."

22. Daniel O'Connor and Phyllis Van Orden, "Getting into Print," College \& Research Libraries

39 (Sept. 1978): 389-96.

23. Budd and Seavey, "Characteristics of Journal Authorship by Academic Librarians."

24. O'Connor and Van Orden, "Getting into Print," 390.

25. Thomas E. Nisonger, "Authorship in Library Acquisitions: Practice \& Theory," Library Acquisitions: Practice \& Theory 20 (1996): 395-419.

26. Watson, "Production of Scholarly Articles by Academic Librarians and Library School Faculty," 335.

27. Krausse and Sieburth, "Patterns of Authorship in Library Journals by Academic Librarians," 128.

28. Budd and Seavey, "Characteristics of Journal Authorship by Academic Librarians," 464.

29. Krausse and Sieburth, "Patterns of Authorship in Library Journals by Academic Librarians," 129.

30. Watson, "Production of Scholarly Articles by Academic Librarians and Library School Faculty," 336.

31. Pettigrew and Nicholls, "Publication Patterns of LIS Faculty from 1982-92," 143.

32. Pamela S. Bradigan and Carol A. Mularski, "Authorship Outlets of Academic Health Sciences Librarians," Bulletin of the Medical Library Association 80 (Apr. 1992): 188-91.

33. John Centra, "Research Productivity and Teaching Effectiveness," Research in Higher Education 18 (1983): 381-83.

34. Ernest L. Boyer, Scholarship Reconsidered: Priorities of the Professoriate (San Francisco: JosseyBass, 1990), table A-19.

35. Peter Hernon and Candy Schwartz, "Library \& Information Science Research-Marking the Journal's 20th Anniversary," Library \& Information Science Research 20 (1998): 309-20.

36. James L. Terry, "Authorship in College $\mathcal{E}$ Research Libraries Revisited: Gender, Institutional Affiliation, Collaboration," College \& Research Libraries 57 (July 1996): 380.

37. Paul Metz "A Statistical Profile of College $\mathcal{E}$ Research Libraries," College \& Research Libraries 50 (Jan. 1989): 42-47.

38. Budd and Seavey, "Characteristics of Journal Authorship by Academic Librarians."

39. Watson, "Production of Scholarly Articles by Academic Librarians and Library School Faculty."

40. Nisonger, "Authorship in Library Acquisitions: Practice \& Theory."

41. Mickey Zemon and Alice Harrison Bahr, "An Analysis of Articles by College Librarians," College \& Research Libraries 59 (1998): 431.

42. Alvin B. Kernan, Death of Literature (New Haven, Conn.: Yale Univ. Pr., 1990). 